\title{
Effect of nitric oxide on postoperative acute kidney injury in patients who underwent cardiopulmonary bypass: a systematic review and meta-analysis with trial sequential analysis
}

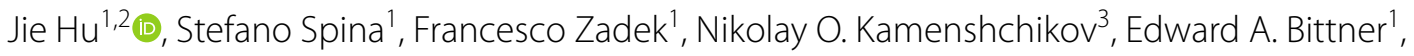
Juan Pedemonte ${ }^{1,4}$ and Lorenzo Berra ${ }^{1^{*}}$ (i)

\begin{abstract}
Background: The effect of nitric oxide (NO) on renal function is controversial in critical illness. We performed a systematic meta-analysis and trial sequential analysis to determine the effect of $\mathrm{NO}$ gas on renal function and other clinical outcomes in patients requiring cardiopulmonary bypass (CPB). The primary outcome was the relative risk (RR) of acute kidney injury (AKI), irrespective of the AKI stage. The secondary outcome was the mean difference (MD) in the length of ICU and hospital stay, the RR of postoperative hemorrhage, and the MD in levels of methemoglobin. Trial sequential analysis (TSA) was performed for the primary outcome.

Results: 54 trials were assessed for eligibility and 5 studies ( 579 patients) were eligible for meta-analysis. NO was associated with reduced risk of AKI (RR 0.76, 95\% confidential interval [CI], 0.62 to $0.93, l^{2}=0 \%$ ). In the subgroup analysis by $\mathrm{NO}$ initiation timing, $\mathrm{NO}$ did not decrease the risk of AKI when started at the end of CPB (RR $1.20,95 \% \mathrm{Cl}$ $\left.0.52-2.78, P^{2}=0 \%\right)$. However, $\mathrm{NO}$ did significantly reduce the risk of AKI when started from the beginning of CPB (RR $0.71,95 \% \mathrm{Cl} 0.54-0.94, P^{2}=10 \%$ ). We conducted TSA based on three trials (400 patients) using KDIGO criteria and with low risk of bias. TSA indicated a $\mathrm{Cl}$ of $0.50-1.02$ and an optimal information size of 589 patients, suggesting a lack of definitive conclusion. Furthermore, NO does not affect the length of ICU and hospital stay or the risk of postoperative hemorrhage. NO slightly increased the level of methemoglobin at the end of CPB (MD 0.52\%, 95\% Cl 0.27-0.78\%, $\left.R^{2}=90 \%\right)$, but it was clinically negligible.
\end{abstract}

Conclusions: NO appeared to reduce the risk of postoperative AKI in patients undergoing CPB. Additional studies are required to ascertain the finding and further determine the dosage, timing and duration of $\mathrm{NO}$ administration.

Keywords: Nitric oxide, Cardiopulmonary bypass, Acute kidney injury, Meta-analysis, Trial sequential analysis

\section{Background}

Acute kidney injury (AKI) is a multifactorial and common complication in patients undergoing cardiopulmonary bypass (CPB), as it occurs in $30-70 \%$ of patients [1-4]. CPB leads to a decrease in the bioavailability of vascular nitric oxide $(\mathrm{NO})$, both because

\footnotetext{
*Correspondence: Iberra@mgh.harvard.edu

1 Department of Anesthesia, Critical Care and Pain Medicine, Massachusetts General Hospital, 55 Fruit Street, Boston, MA, USA Full list of author information is available at the end of the article
}

of NO scavenging (via deoxygenation reaction in the presence of intravascular hemolysis $[5,6]$ ) and through a reduction in NO synthesis (in the presence of ischemia/reperfusion injury, acute inflammatory reaction and endothelial dysfunction [7]). In particular, hemolysis generated during the $\mathrm{CPB}$ has been demonstrated to be a pivotal contributor to the increased risk of perioperative AKI in patients undergoing CPB [6].

NO regulates vascular tone and distal blood perfusion while also acting as an anti-inflammatory and 
anti-thrombotic mediator [8]. NO gas is traditionally used for the treatment of acute exacerbation of pulmonary hypertension [9] and pediatric hypoxemic respiratory failure [10]. At present, NO has been tested in several randomized trials for its protective role in pulmonary hypertension and myocardial injury in patients undergoing CPB [11-13]. More recently, NO has been shown to protect against AKI and chronic renal disease, either by reprogramming metabolism [14] or via homeostatic regulation of renal hemodynamics and $\alpha 1$-adrenoreceptor sensitization [15]. Administration of $\mathrm{NO}$ gas was associated with benefit of lowering plasma NO consumption in the presence of hemolysis $[16,17]$. Lei et al. conducted a singlecenter randomized controlled trial (RCT) and found that NO delivered from the beginning of $\mathrm{CPB}$ could reduce the risk of AKI and lower NO consumption in plasma [18], a finding which was confirmed by a recently completed randomized trial [19]. On the contrary, in a meta-analysis, Ruan et al. showed that NO therapy was associated with renal dysfunction, especially in critically ill patients with acute respiratory distress syndrome (ARDS) [20].

We hypothesized that the effect of NO on kidney function might be disease specific, as two of the RCTs in the meta-analysis of Ruan et al. [20] showed that $\mathrm{NO}$ administration started from the end of CPB in cardiac surgery patients [21, 22] had no adverse effects on renal function. Thus, a careful analysis of the effect of NO gas on renal function in cardiac surgery is warranted.

We performed a meta-analysis aiming to ascertain the effect of NO therapy on renal function in patients undergoing $\mathrm{CPB}$ and to further investigate whether the effect of NO varies between different initiation time points of such therapy.

\section{Methods}

This systematic review and meta-analysis was registered on PROSPERO (NO. CRD42019125948) based on the Preferred Reporting Items for Systematic Reviews and Meta-Analyses (PRISMA) guidelines [23].

\section{Search strategy}

Two trained investigators (J.H. and J.P.) independently searched pertinent studies in PubMed, Cochrane Central Register of Controlled Trials (CENTRAL), Embase, Web of Science, and Clinicaltrial.gov from inception through December 2018, with the help of a librarian from the Countway Library at Harvard Medical School. Details of our search strategy are described in Additional file 1 (data not shown).

\section{Study selection}

Two investigators (J.H., J.P.) independently searched if the eligible studies met the following PICOS criteria: (1) population: patients undergoing CPB; (2) intervention: NO delivery either from the beginning of $\mathrm{CPB}$ or at the end of $\mathrm{CPB}$; (3) comparison intervention: placebo or no therapy; (4) outcome: the relative risk of postoperative AKI; and (5) study design: randomized controlled trials (RCTs).

There were no restrictions on the dose or time of NO administration. We included unpublished trials only if trial data and methodological descriptions were provided either in written form or could be retrieved from the trial authors. No language restriction was enforced. The exclusion criteria included crossover trials and studies not reporting the renal outcome.

\section{Data extraction and study characteristics}

Two authors (J.H. and J.P.) independently assessed the selected studies for the final analysis, with disagreements resolved by discussion and, if needed, via a third author (LB), who acted as an adjudicator. A standardized recording form was used for data extraction.

The primary outcome was the risk of AKI, irrespective of the AKI stage. The secondary outcome was as follows: the length of ICU and hospital stay, the risk of postoperative hemorrhage (i.e., requiring blood transfusion after the operation or reoperation), and the levels of methemoglobin (MetHb) at the end of CPB.

\section{Assessment of risk of bias}

Quality assessment of the screened studies was performed using the Cochrane Collaboration tool [24] by two independent authors (J.H. and J.P.), and discrepancies were resolved by consensus. The following domains were evaluated individually and graded as "low risk", "high risk", or "unclear risk": random sequence generation, allocation concealment, blinding of participants and personnel, blinding of outcome assessment, incomplete outcome data, selective outcome reporting, and other bias.

\section{Data analysis and synthesis}

We calculated the pooled risk ratios (RR) and 95\% confidence intervals (CI) for the binary outcome of AKI, and postoperative hemorrhage using the Mantel-Haenszel method with the random-effects model. We estimated the mean difference (MD) and 95\% CI for continuous outcomes of the length of ICU and hospital stay and the levels of MetHb using the inverse variance method with the random-effects model. If continuous variables were 
expressed as a median and interquartile range, the mean and standard deviation were computed based on the median, interquartile range, and sample size as described elsewhere [25].

Considering that the inclusion of fewer than ten studies in meta-analysis causes low statistical power for detecting funnel plot asymmetry [26], we assessed the risk of publication bias by visual examination of the funnel plot. To assess and adjust for potential publication bias in the meta-analysis, we performed the trim-and-fill test [27]. The amount of heterogeneity was assessed by both Cochran's Q test and the $I^{2}$ statistic [28].

We performed a subgroup analysis to investigate whether the effect of NO on AKI varied based on the timing of NO therapy initiation, i.e., starting from the beginning of $\mathrm{CPB}$ or at the end of $\mathrm{CPB}$ (immediately before the weaning of $\mathrm{CPB}$ ).

We performed sensitivity analyses to determine the robustness of the effect size using different data analysis methods. First, we used the Peto method, since it may be the least biased in the presence of sparse data and imbalance of sample size within trials [29]. Second, to reduce the intrinsic heterogeneity among studies based on the outcome measure, we omitted the two studies that did not use the KDIGO criteria in AKI and repeated the evaluation.

We conducted trial sequential analysis (TSA) to quantify the statistical reliability of data in the cumulative meta-analysis and adjusted significance levels for the risk of random errors due to repetitive testing on accumulating data [30]. For this analysis, we employed a randomeffects model using the DerSimonian-Laird Method and included trials with low risk of bias and that used the KDIGO criteria for AKI diagnosis. We intended to maintain an overall $5 \%$ risk of a type I error and a power of $80 \%$. For the calculation of the required IS, we anticipated an intervention effect of a $30 \%$ relative risk reduction (RRR) as suggested by Lei et al. [18]. We used a control event proportion calculated from the actual meta-analysis. We calculated TSA-adjusted CI (alpha spending) for effect size.

Statistical analyses were conducted using Review Manager v.5.3 (The Nordic Cochrane Centre, The Cochrane Collaboration, Copenhagen, Denmark), Trial Sequential Analysis v.0.9.5.10 beta (Copenhagen Trial Unit, Centre for Clinical Intervention Research, Rigshospitalet, Copenhagen, Denmark, available from http://www.ctu. $\mathrm{dk} / \mathrm{tsa}$ ) and R v.1.1.456 (R Core Team, R Foundation for Statistical Computing, Vienna, Austria) with the "metafor" and "meta" packages.

\section{Results}

\section{Literature search and study characteristics}

Through the electronic search, 5376 citations were identified. After excluding 1293 duplicates, 4083 studies were chosen for further evaluation. Through reading the titles and abstracts, 4029 ineligible studies were excluded, and 54 studies were identified as potentially eligible for inclusion and were evaluated by reading the full text. Fortyeight studies were excluded due to lack of full text, not randomized for NO therapy or crossover studies, not reporting renal outcomes, and using peritoneal dialysis as readily therapy. Finally, six studies were eligible for systematic review [18, 19, 21, 22, 31, 32]. Among the six included studies, one study was ultimately excluded, because not all the patients in $\mathrm{NO}$ and control groups underwent $\mathrm{CPB}$ [32]. One study was completed recently and relevant data were obtained from the primary investigator (N. Kamenshchikov) [19]. Figure 1 shows the process of literature selection and reasons for study exclusion.

The characteristics of the included studies are summarized in Table 1. These studies vary in AKI definition and in the time of initiation of NO therapy. Two studies started NO therapy immediately before CPB weaning $[21,22]$ and defined renal dysfunction as urine output less than $0.3 \mathrm{ml} / \mathrm{h}$ [21] or need for renal replacement treatment (RRT) [22], respectively. Three studies delivered NO from the beginning of CPB and defined AKI by the KDIGO criteria [18, 19, 31]. Detailed information of all included studies is shown in Table 1, and quality evaluation is shown in Fig. 2 and Additional file 2 (data not shown).

\section{Quantitative data synthesis}

For the primary outcome of AKI irrespective of the stage, the pooled effect showed that NO therapy significantly reduced the risk of AKI with RR of 0.76 (95\% CI $0.62-$ $0.93, I^{2}=0 \%, p=0.008$, Fig. 3a).

To evaluate the impact of the timing of NO therapy initiation on the development of AKI, we performed a subgroup analysis. NO therapy did not appear to decrease the risk of AKI when it started immediately before the weaning of CPB (RR, 1.20, 95\% CI 0.52-2.78, $p=0.67, I^{2}=0 \%$, Fig. 3b). Conversely, NO did appear to significantly reduce the risk of AKI when administered from the beginning of CPB (RR, 0.71, 95\% CI 0.54-0.94, $p=0.02, I^{2}=10 \%$, Fig. $3 \mathrm{~b}$ ).

The funnel plot based on the primary outcome (Additional file 3, data now shown) showed asymmetry on visual inspection. This suggests that the pooled effect from the current data might overestimate the improvement of NO on renal function. We performed the trimand-fill test to adjust the publication bias. It confirmed the benefit of $\mathrm{NO}$ on renal function with adjusted $\mathrm{RR}$ of 0.77 (95\% CI 0.62-0.94, $p=0.01, I^{2}=0 \%$, Fig. 4a, b).

Sensitivity analyses were performed to evaluate the influence of data synthesis methods on the estimate 


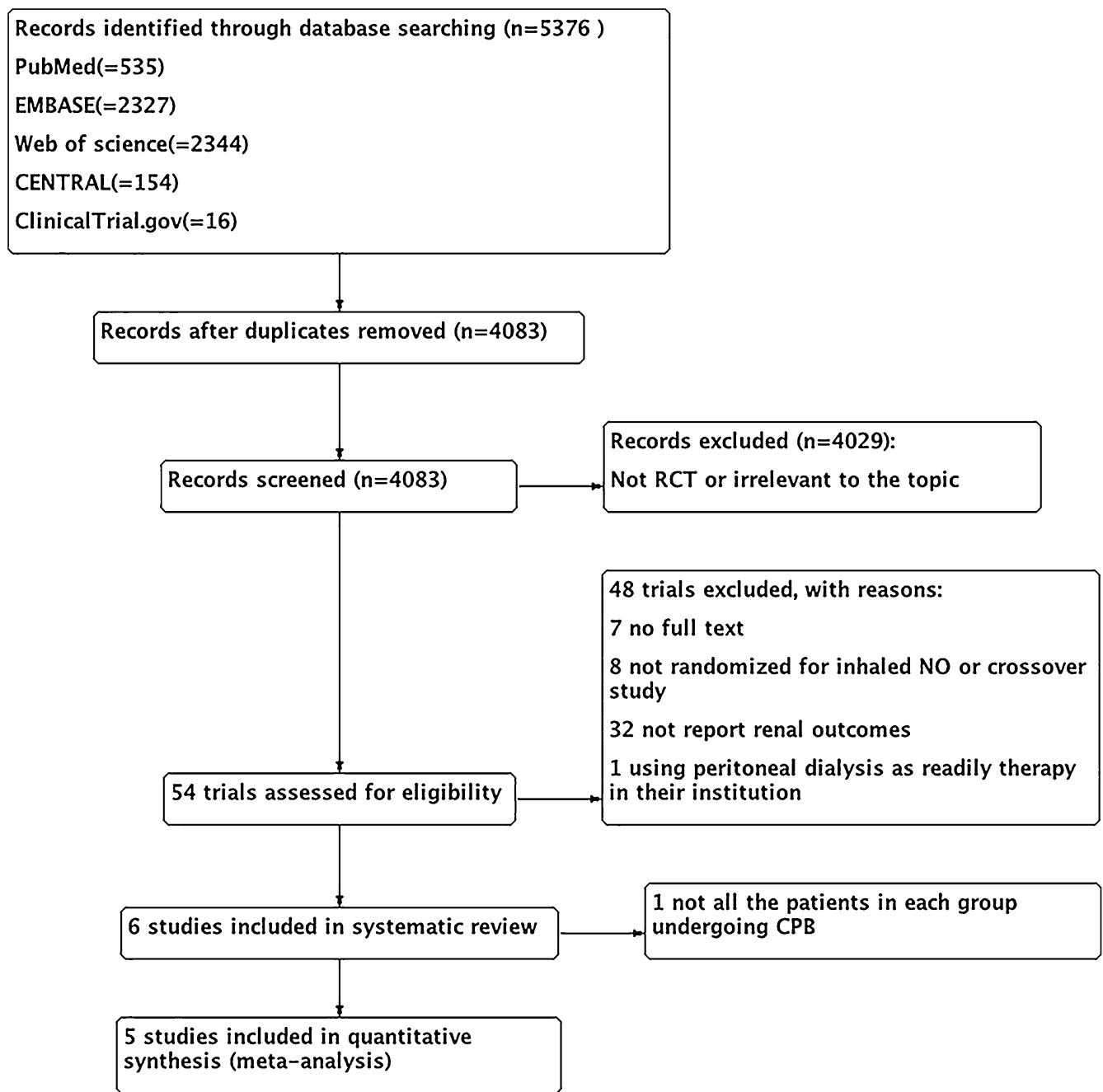

Fig. 1 Flow chart of the systematic review and meta-analysis in the present study

of the summary effect. First, to evaluate the potential impact of the sparse data and imbalance of sample size, we pooled the effect sizes by the Peto method and found that it was similar to that obtained by the primary analysis (Table 2, Additional file 4, data not shown). Second, the three studies that had low risk of bias and reported AKI using KDIGO criteria [18, 19, 31] were included in a sensitivity analysis. Data also corroborated the beneficial effect of NO on renal function (RR, 0.71, 95\% CI $0.54-0.94, p=0.02, I^{2}=10 \%$, Additional file 5 , data not shown).

To decrease the risk of random errors due to sparse data or repetitive testing and calculate the optimal information size for this meta-analysis, we performed TSA based on three trials that used KDIGO criteria and were considered to have a low risk of bias (400 patients). Although the cumulative $Z$ curve crossed the traditional boundary for statistical significance, it did not cross the
TSA monitoring boundary or reach the information size (Fig. 5). Based on this analysis, the optimal information size was found to be 589 patients for risk of AKI. The alpha spending adjusted CI was $0.50-1.02\left(I^{2}=10 \%\right.$, $D^{2}=44 \%$ ) based on $30 \%$ RRR (from a baseline event rate of $50.8 \%$ ).

For the secondary outcomes, there appeared to be no benefit of NO on the length of ICU and hospital stay, with MD of -0.09 day $\left(95 \% \mathrm{CI}-0.22-0.03, p=0.15, I^{2}=0 \%\right.$, Additional file 6, data not shown) and MD of -0.51 day (95\% CI - 1.17-0.16, $p=0.14, I^{2}=27 \%$, Additional file 7, data not shown), respectively.

The effect of NO administration during CBP on hemorrhage was examined as a potential complication. $\mathrm{NO}$ administration did not increase the risk of postoperative hemorrhage in patients undergoing $\mathrm{CPB}$ with RR 0.79 (95\% CI 0.22-2.83, $p=0.71, I^{2}=35 \%$, Additional file 8 , data not shown). 
Table 1 Details of the included randomized controlled trials

\begin{tabular}{|c|c|c|c|c|c|c|c|c|}
\hline \multirow[t]{2}{*}{ Study (year) } & \multirow[t]{2}{*}{ Population } & \multirow[t]{2}{*}{$\begin{array}{l}\text { The protocol } \\
\text { of NO therapy }\end{array}$} & \multirow[t]{2}{*}{ Comparison } & \multirow[t]{2}{*}{ Definition of AKI } & \multicolumn{2}{|c|}{ Duration of CPB (min) } & \multicolumn{2}{|c|}{$\begin{array}{l}\text { No. of AKI/no. } \\
\text { of cases }\end{array}$} \\
\hline & & & & & NO & Control & $\overline{\text { NO }}$ & Control \\
\hline Potapov (2011) & $\begin{array}{r}\text { Adults, LVAD } \\
\text { placement }\end{array}$ & $\begin{array}{l}40 \text { ppm within } \\
48 \mathrm{~h} \text {, through } \\
\text { inhalation }\end{array}$ & Placebo & Need for RRT & NA & NA & $10 / 73$ & $8 / 77$ \\
\hline Fernandes (2011) & $\begin{array}{l}\text { Adults, mitral ste- } \\
\text { nosis and severe } \\
\text { pulmonary } \\
\text { hypertension }\end{array}$ & $\begin{array}{l}10 \text { ppm within } \\
48 \mathrm{~h} \text {, through } \\
\text { inhalation }\end{array}$ & Oxygen & $\begin{array}{l}\text { Urine out- } \\
\text { put }<0.3 \mathrm{ml} / \\
\mathrm{kg} / \mathrm{h}\end{array}$ & $88 \pm 31^{\#}$ & $94 \pm 34^{\#}$ & $0 / 14$ & $1 / 15$ \\
\hline Lei (2018) & $\begin{array}{l}\text { Adults, multiple } \\
\text { valve replace- } \\
\text { ment surgery, } \\
\text { mostly due to } \\
\text { rheumatic fever }\end{array}$ & $\begin{array}{l}80 \mathrm{ppm} \text { within } \\
24 \mathrm{~h} \text {,through } \\
\text { CPB and inhala- } \\
\text { tion }\end{array}$ & Placebo & $\begin{array}{l}\text { KDIGO criteria } \\
\text { (SCr only) }\end{array}$ & $138(122 ; 159)^{\xi \&}$ & $134(114 ; 154)^{\&}$ & $58 / 117$ & $81 / 127$ \\
\hline $\begin{array}{l}\text { Kamenshchikov } \\
\text { (2018) }\end{array}$ & Adults, CABG & $\begin{array}{l}40 \mathrm{ppm} \text { through } \\
\text { CPB }\end{array}$ & Standard CPB & $\begin{array}{c}\text { KDIGO criteria } \\
(\mathrm{SCr} \text { only) })^{*}\end{array}$ & $110(85.8 ; 137)^{\&}$ & $116(88.8 ; 129.5)^{\&}$ & $1 / 30$ & $3 / 30$ \\
\hline $\begin{array}{l}\text { Kamenshchikov } \\
\text { (2019) }\end{array}$ & $\begin{array}{l}\text { Adults, CABG, } \\
\text { valve surgery, } \\
\text { surgical recon- } \\
\text { struction of the } \\
\text { left ventricle }\end{array}$ & $\begin{array}{l}40 \mathrm{ppm} \text { through } \\
\text { CPB }\end{array}$ & Standard CPB & $\begin{array}{l}\text { KDIGO criteria } \\
\text { (SCr and urine } \\
\text { output) }\end{array}$ & $118(95.5 ; 167.5)^{\&}$ & $119(91.7 ; 130.4)^{\&}$ & $10 / 48$ & $20 / 48$ \\
\hline
\end{tabular}

LVAD left ventricular assist device, $A K I$ acute kidney injury, $C A B G$ coronary artery bypass grafting, $C P B$ cardiopulmonary bypass; placebo, an equivalent concentration of nitrogen; KDIGO criteria* only monitoring for 2 days after operation, $R R T$ renal replacement therapy; through inhalation ${ }^{\#}$ started NO administration immediately at the discontinuation of $\mathrm{CPB} ;{ }^{\$} p=0.048 ;{ }^{\#}$ mean $\pm \mathrm{SD} ;{ }^{\&}$ median (interquartile range)

As safety outcome, levels of MetHb at the end of CPB were also evaluated. Since Lei et al. measured the levels of MetHb at different time points, which peaked at the end of the CPB [18], the levels of MetHb at the end of CPB were studied and showed NO increased levels of MetHb with MD of $0.52 \%$ (95\% CI $0.27-0.78 \%, p<0.001$, $I^{2}=90 \%$ ) (Additional file 9, data not shown).

\section{Discussion}

In this study, we investigated the effect of NO therapy on the risk of postoperative $\mathrm{AKI}$ in patients undergoing $\mathrm{CPB}$. Overall, NO reduced the incidence of AKI in patients undergoing $\mathrm{CPB}$. Although visual inspection of the funnel plot suggested publication bias, the trim-and-fill test still confirmed a beneficial effect of $\mathrm{NO}$ administration on the development of AKI. Sensitivity analyses also revealed consistent effect estimates for the primary outcome. However, TSA analysis suggests that further studies are required to achieve a firm conclusion. NO supplementation neither reduced the length of the hospital or ICU stay nor increased the risk of postoperative hemorrhage. NO therapy slightly increased the level of MetHb, which was clinically negligible and always below safety thresholds.

The nephrotoxicity of NO therapy has emerged since the aforementioned meta-analysis was published [20], which suggested that NO impaired renal function in critical illness settings. To interpret our results in the contest of the present literature, we asked two questions.
Our first question is: why has NO therapy shown differing effects on renal function in patients undergoing $\mathrm{CPB}$ as compared to patients with ARDS [20]? Several mechanisms may explain the contradictory scenario. CPB contributes to the development of AKI through multiple mechanisms including [1] hypoperfusion (microcirculatory), [2] ischemia/reperfusion injury, [3] hemodilution, [4] pro-inflammatory response, and most importantly, and [5] intravascular hemolysis [33]. Hemolysis strongly correlates to increased plasma $\mathrm{NO}$ depletion leading to a decrease of $\mathrm{NO}$ bioavailability $[6,34]$. Nitric oxide is a potent endogenous vasodilator released by endothelial cells and its depletion leads to vasoconstriction, and ultimately to reduce organ perfusion $[17,35,36]$. The renal protective effects of $\mathrm{NO}$ gas might be twofold. On one hand, the administration of NO may act as the replenishment of NO storage in the presence of NO depletion due to hemolysis. On the other hand, NO gas might generate plasma NO metabolites that are protective against ischemia-reperfusion injury [37]. In this context, administration of therapeutic NO has shown promising properties by lowering vascular NO depletion [16], which could explain why breathing 40 parts per million (ppm) of NO markedly increased renal blood flow, glomerular filtration rate, and urine flow in a swine model of phenylephrine-induced hypertension [38].

In comparison, there is no obvious NO deficiency in ARDS. Instead, intrapulmonary NO generation due to 


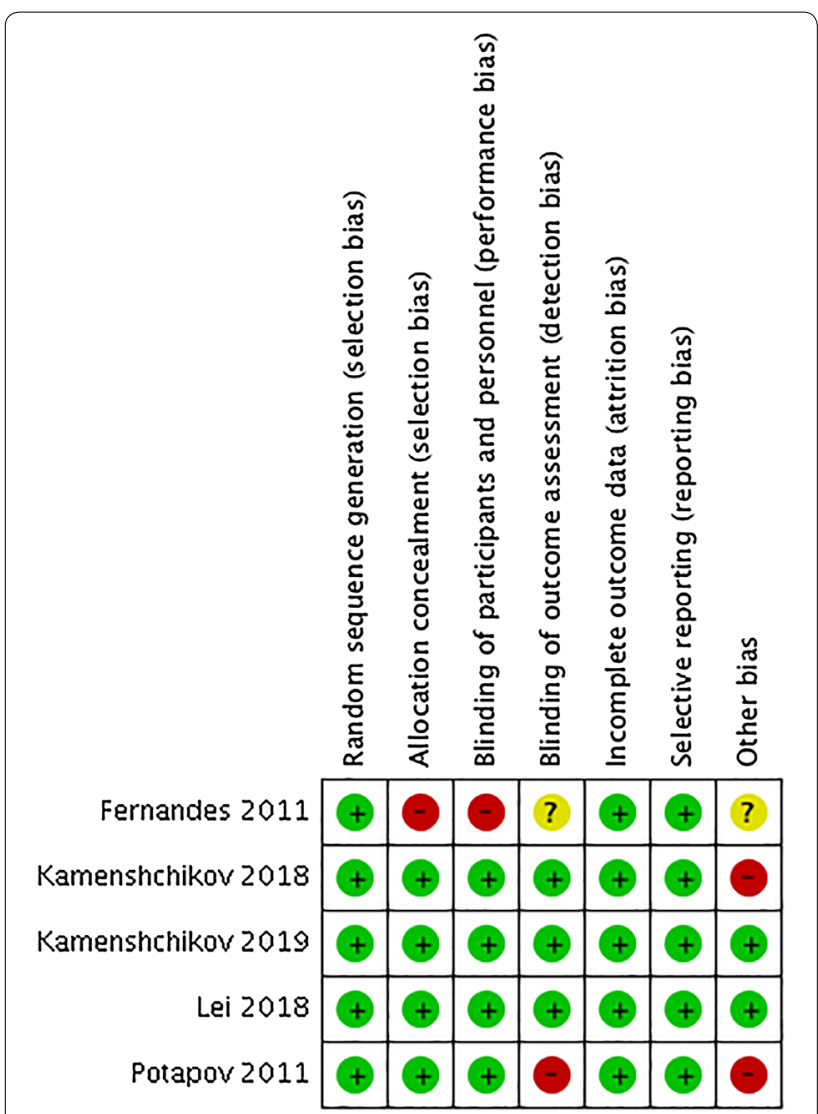

Fig. 2 Risk of bias summary for each included trial. Red circles indicate high risk. Green circles indicate low risk. Yellow circles indicate unclear risk

inducible NO synthase was found in an experimental model of endotoxemia-induced ARDS and finally proved to be involved in the development of ARDS [39]. Moreover, Ruan et al. found that the duration of NO administration was longer in ARDS studies (> 7 days) [20]. Thus, prolonged NO therapy could induce plasma NO redundancy and in turn [1] induce tubular apoptosis [40], [2] produce reactive nitrogen species, such as nitrogen dioxide $\left(\mathrm{NO}_{2}\right)$ [41], and create a pro-inflammatory response leading to renal vasoconstriction and injury [20]. Based on present literature, we suggested that the effect of NO on renal function might be disease specific.

Our second question is: does the effect of $\mathrm{NO}$ on renal function vary by the timing of initiation? To answer to this question, one should consider the differences in renal dysfunction definition adopted in the five studies included in our meta-analysis. The first two studies in which $\mathrm{NO}$ was administrated at the end of $\mathrm{CPB}$, renal dysfunction was defined as severe AKI (i.e., urine output $<0.3 \mathrm{ml} / \mathrm{kg} / \mathrm{h}$ [21] or need for renal replacement therapy [22]). In the following three studies [18, 19, 31] in which $\mathrm{NO}$ gas was delivered at the beginning of $\mathrm{CPB}$, renal dysfunction followed KDIGO criteria. Due to the dissimilar definitions of renal injury, we are unable to make a definitive conclusion on the renal protective properties of NO delivery when started at the end of $\mathrm{CPB}$. Indeed, based on biochemical [6,33,42-44] and hemodynamic studies [45-50] discussed below, it is plausible that late delivery of $\mathrm{NO}$ might not protect the kidney function.

Red blood cells (RBCs) are damaged when passing through the CPB circuit [33] and thus releasing free hemoglobin $(\mathrm{Hb})$ into the circulation [42]. High levels and prolonged duration of hemolysis can scavenge the NO produced by the endothelial cells, with deleterious effects on vascular endothelium and renal tubular cells $[33,43]$. Vermeulen et al. showed that patients with postoperative AKI had higher levels of plasma $\mathrm{Hb}$ at the end of $\mathrm{CPB}$, as compared to patients without AKI [6]. Meanwhile, circulating $\mathrm{Hb}$ also promotes oxidative stress and degrades to release free heme and heme iron, triggering the activation of the immune response through the innate pathway (e.g., TLR-4 pathway) [43]. Based on current knowledge, drugs that could prevent endothelial dysfunction by scavenging free $\mathrm{Hb}$ and reactive oxygen species could be a future therapeutic option. If $\mathrm{NO}$ is delivered at the beginning of $\mathrm{CPB}$, it can oxidize heme iron to the ferric state and transform hemoglobin to MetHb [44] before the blood is reinfused in the patient. As a result, plasma availability of $\mathrm{NO}$ is preserved; blood flow to the organs is maintained, thereby lowering the risk of perioperative AKI. If $\mathrm{NO}$ is delivered at the end of $\mathrm{CPB}$, especially when prolonged, hemolysis-associated consequences have already started and subsequently induce AKI via systemic vascular injury, inflammatory cascade, and oxidative stress.

Moreover, hemolysis-induced NO consumption increased pulmonary vascular resistance [34], thereby leading to right heart dysfunction and subsequent postoperative AKI [51]. However, administration of NO at the end of CPB [21, 22, 45-48] or even later in the intensive care unit $[49,50]$ showed no effect on pulmonary hypertension. Among the five studies included in our metaanalysis, Fernandes et al. demonstrated that patients receiving inhaled NO had decreased pulmonary vascular resistance but a similar pulmonary artery systolic pressure, compared to the control group [21]. Potapov et al. found that inhaled NO did not affect right heart function in terms of risk of right heart disease, pulmonary vascular resistance index, and incidence of central venous pressure more than $16 \mathrm{cmH}_{2} \mathrm{O}$ [22]. Furthermore, in other clinical trials assessing effect of $\mathrm{NO}$ on pulmonary hypertension or heart function among patients requiring $\mathrm{CPB}$, administration of $\mathrm{NO}$ at the end of $\mathrm{CPB}$ [45-48] or in the intensive care unit $[49,50]$ did not affect the mean 

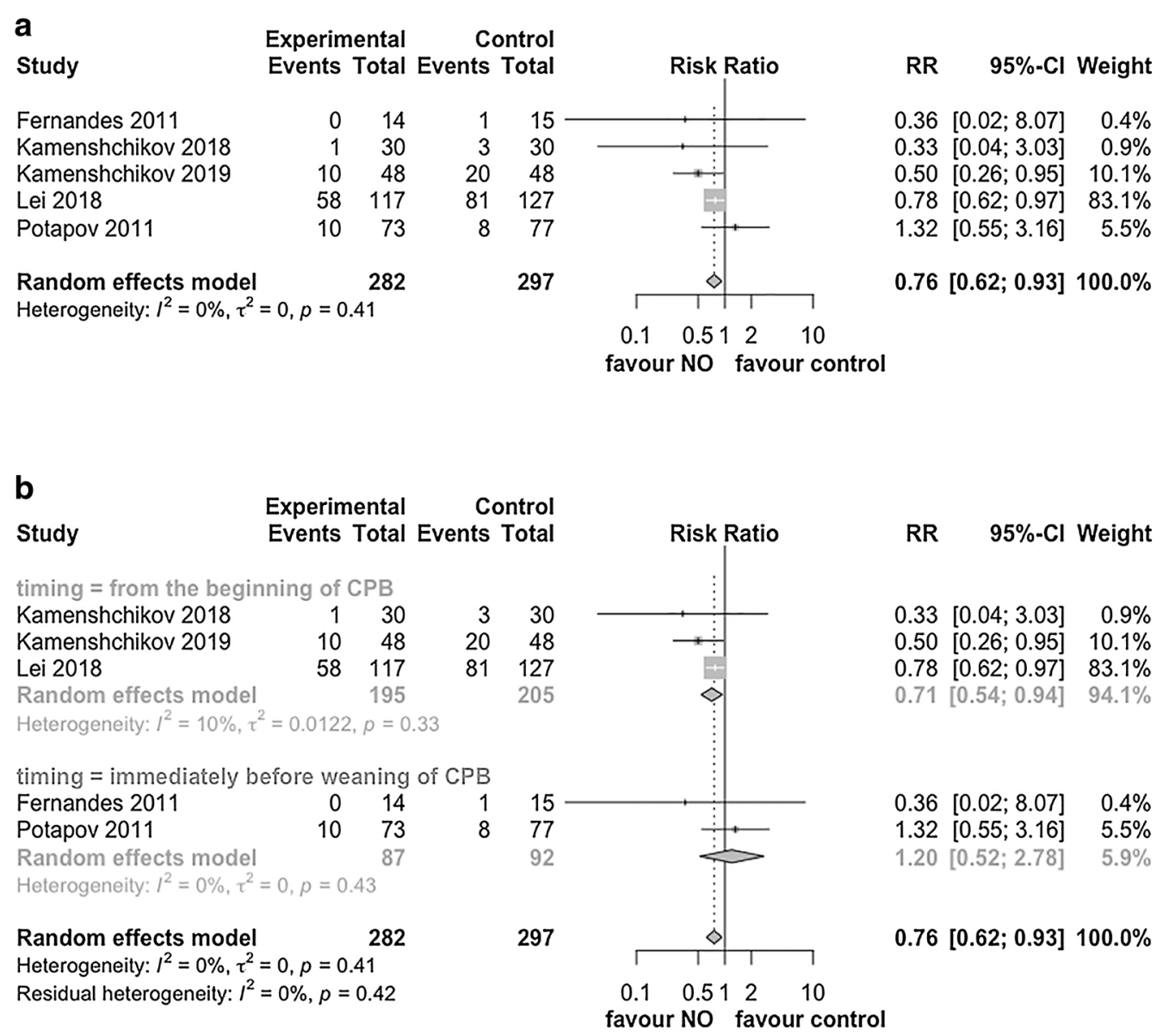

Fig. 3 The relative risk of postoperative AKI. a Forest plot of the risk of AKI irrespective of the AKI stage in included trials. $\mathbf{b}$ Forest plot of subgroup analysis by the timing of NO initiation. RR risk ratio, Cl confidential interval, AKI acute kidney injury, NO nitric oxide

pulmonary artery pressure, and a subsequent meta-analysis also confirmed the aforementioned phenomenon [52]. Further hemodynamic studies should determine whether NO delivered at the beginning of CPB could improve right heart function and pulmonary hypertension, to better interpret the potential mechanism of $\mathrm{NO}$ in renal protection.

Although NO appears to improve renal function in patients requiring $\mathrm{CPB}$, possible adverse effects need to be monitored during gas delivery. Hemorrhage is one of the common concerns of NO treatment in cardiac surgery patients undergoing $\mathrm{CPB}$. NO ha been shown to inhibit platelet activation in in vitro studies [53] and potentially prolong bleeding time. However, no clinical trials showed an increased risk of bleeding when $\mathrm{NO}$ was delivered in cardiac surgery. We confirmed those findings with the present meta-analysis.

The monitoring of MetHb levels in the blood is warranted during $\mathrm{NO}$ delivery. MetHb $\left(\mathrm{Fe}^{3+}\right)$ has a lower capacity to bind oxygen compared to oxy-hemoglobin $\left(\mathrm{Fe}^{2+}\right)$, which may lead to decreased delivery of oxygen to the peripheral tissues and, consequent, tissue hypoxia. It is generally accepted that blood MetHb levels in healthy individuals is less than $2 \%$ of the hemoglobin [54]. Cyanosis is present when the MetHb levels approach 15-20\% [54]. Our metaanalysis showed a slight increase in blood MetHb level in the NO group and never exceeded $10 \%$ in any patient according to the included RCTs $[18,19]$. Meanwhile, Potapov et al. reported that levels of MetHb were not higher in NO group compared with the control group [22] and Kamenshchikov et al. found out that all the patients in their study had levels of MetHb less than $0.5 \%$ during CPB [31].

This study has some limitations. First, the small number of studies included in our meta-analysis may have reduced the statistical power of the analysis. To balance our interpretation, we performed trial sequential analysis, which accounts for the type I, and type II errors, using widely accepted, methods for adjusting thresholds for significance in randomized clinical trials when the required sample size has not been reached [30]. 


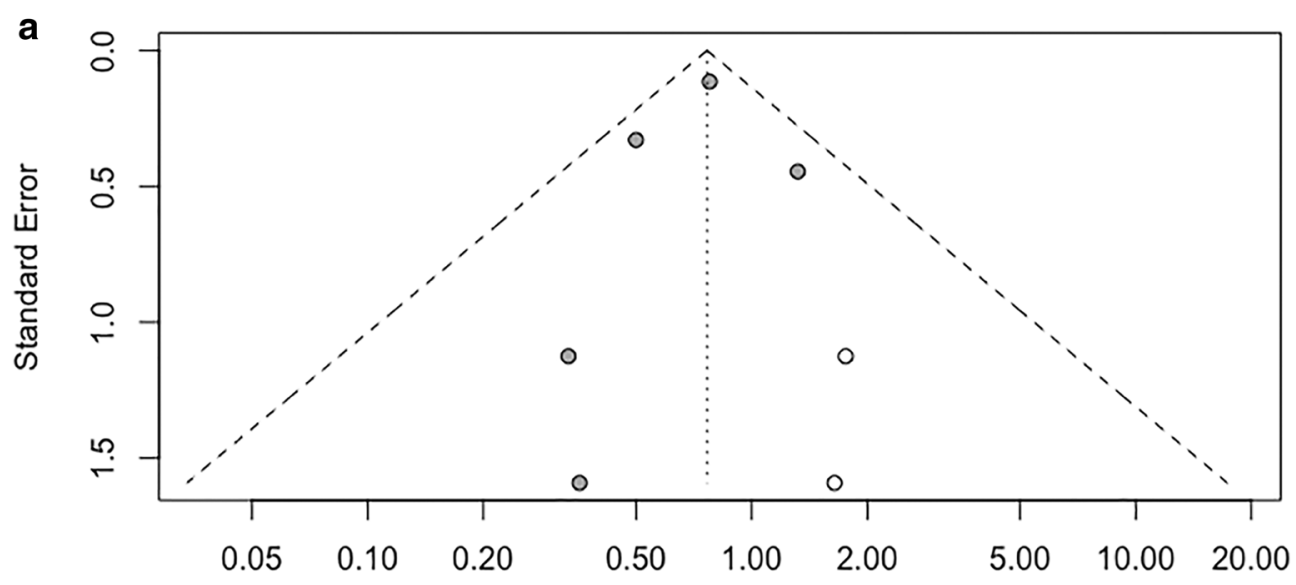

b

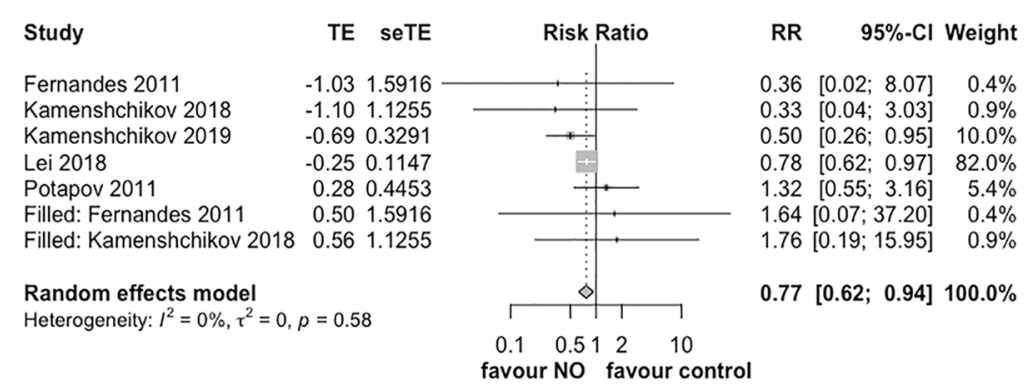

Fig. 4 Trim-and-fill test for the primary outcome. a Funnel plot of the trim-and-fill test. Solid dots indicate included trials. Blanks dots indicated filled unpublished studies. b Forest plot of the trim-and-fill test for the primary outcome. RR risk ratio, Cl confidential interval, AKI acute kidney injury, NO nitric oxide

Table 2 Sensitivity analyses

\begin{tabular}{|c|c|c|c|c|c|}
\hline $\begin{array}{l}\text { Outcome } \\
\text { measures }\end{array}$ & $\begin{array}{l}\text { Number of studies (number } \\
\text { of patients) }\end{array}$ & Statistical model & Effect size $(95 \% \mathrm{Cl})$ & $\begin{array}{l}p \text { value (test } \\
\text { for effect) }\end{array}$ & $\begin{array}{l}\text { Heterogeneity } \\
\left(I^{2}\right), \%\end{array}$ \\
\hline \multirow[t]{3}{*}{ AKI } & $5(597)$ & RR random effects & $0.76(0.62-0.93)$ & 0.008 & 0 \\
\hline & & OR random effects & $0.58(0.38-0.90)$ & 0.015 & 6 \\
\hline & & OR Peto & $0.58(0.37-0.92)$ & 0.019 & 12 \\
\hline AKI & $3(400)$ & RR random effects & $0.71(0.54-0.94)$ & 0.018 & 10 \\
\hline
\end{tabular}

$A K l$ acute kidney injury, $R R$ risk ratio, $O R$ odds ratio

Second, although the level of statistical heterogeneity was very low in our analyses, the heterogeneity in other independent variables including AKI diagnosis criteria, duration and dosage of NO therapy, and time of $\mathrm{CPB}$ should not be overlooked. Over the past decades, the diagnostic criteria for AKI and AKI stage definitions have changed, i.e., decades ago common medical terminology referred to acute renal failure to describe kidney injury in acute settings, subsequently, the RIFLE criteria introduced the term AKI [55], the AKIN perfected the definition of AKI [56] and more recently those definitions have been updated in KDIGO classification [57]. Thus, it is not surprising that many meta-analyses and epidemiological studies reported in the literature include heterogeneous AKI definitions [20, 58].

Finally, some competing endpoints, such as 28- or 90-day mortality, the impact of different dose and duration of NO on renal function, and the right heart function were not reported in the present study.

\section{Conclusion}

In our meta-analysis, we found that $\mathrm{NO}$ appeared to reduce the risk of postoperative $\mathrm{AKI}$ in patients undergoing $\mathrm{CPB}$, suggesting that the effect of $\mathrm{NO}$ on renal function might be disease specific. Future trials 


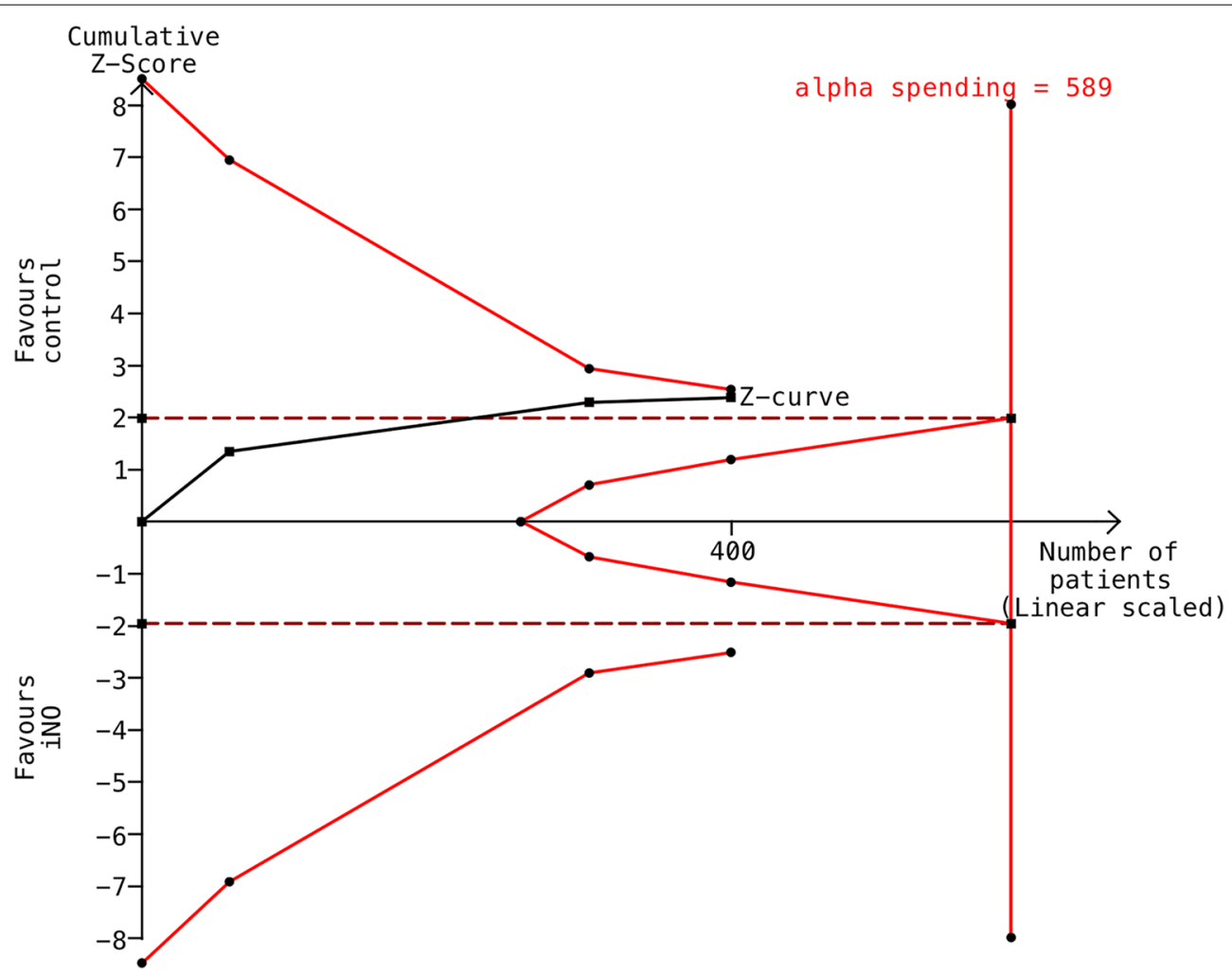

Fig. 5 Trial sequential analysis (TSA) for the primary outcome. The TSA of the included trials (black square fill icons) shows that the cumulative $Z$ curve did cross the traditional boundary (wine red dotted line) but did not cross the trial sequential monitoring boundary (red full line) for futility or reach the required information size $(n=589)$. $X$-axis: the number of patients randomized; $y$-axis: the cumulative $z$ score; horizontal wine red dotted lines: conventional boundaries (upper for benefit, $z$ score $=1.96$, lower for harm, z score $=-1.96$, two-sided, $p=0.05$ ); oblique red lines with black full circle icons: trial sequential monitoring boundaries; oblique black line with black full square icons: $Z$ curve; and vertical red straight line with circles: required information size. The diversity-adjusted required information size (589 participants) was based on a relative risk reduction of $30 \%$, an alpha of $5 \%$, a beta of $20 \%$, and an event proportion of $50.7 \%$ in the control arm. The red cumulative $Z$ curve was constructed using a random-effects model with the DerSimonian-Laird Method

involving NO therapy are required to consolidate our findings and investigate potential mechanisms of renal protection properties.

\section{Supplementary information}

Supplementary information accompanies this paper at https://doi. org/10.1186/s13613-019-0605-9.

Additional file 1. Search strategy.

Additional file 2. Risk of bias graph.

Additional file 3. Funnel plot for the primary outcome.

Additional file 4. Forest plot for the Peto method. OR, odds ratio. Cl, confidential interval; AKI, acute kidney injury; NO, nitric oxide.

Additional file 5. Forest plot for sensitivity analysis including studies that had lower risk of bias and reported AKI using KDIGO criteria. RR, risk ratio. $\mathrm{Cl}$, confidential interval; $\mathrm{AKl}$, acute kidney injury; $\mathrm{NO}$, nitric oxide.

Additional file 6. Forest plot for the length of ICU stay. MD, mean difference. SD, standard deviation; $\mathrm{Cl}$, confidential interval; $\mathrm{NO}$, nitric oxide.

Additional file 7. Forest plot for the length of hospital stay. MD, mean difference. SD, standard deviation; $\mathrm{Cl}$, confidential interval; $\mathrm{NO}$, nitric oxide.
Additional file 8. Forest plot for the risk of postoperative hemorrhage, i.e., requiring blood transfusion after the operation or reoperation. RR, risk ratio. $\mathrm{Cl}$, confidential interval; $\mathrm{NO}$, nitric oxide.

Additional file 9. Forest plot for levels of methemoglobin at the end of $\mathrm{CPB}, \%$. MD, mean difference. SD, standard deviation; $\mathrm{Cl}$, confidential interval; $N O$, nitric oxide; $C P B$, cardiopulmonary bypass.

\section{Abbreviations}

AKI: Acute kidney injury; ARDS: Acute respiratory distress syndrome; CPB: Cardiopulmonary bypass; $\mathrm{Cl}$ : Confidence interval; $\mathrm{Hb}$ : Hemoglobin; ICU: Intensive care unit; MetHb: Methemoglobin; $\mathrm{NO}_{2}$ : Nitrogen dioxide; MD: Mean difference; RR: Relative risk; RCT: Randomized controlled trial; RRT: Renal replacement therapy; RBCs: Red blood cells; TSA: Trial sequential analysis; RIFLE: Risk, injury, failure, loss and end of stage; AKIN: Acute kidney injury net; KDIGO: Kidney disease: improving global outcomes.

\section{Acknowledgements}

The authors thank Brian Healy, Miguel Hernán, Barbra Dickerman and Scott Lapinski at Harvard Medical School.

\section{Authors' contributions}

$\mathrm{JH}$ conceived of and designed the study. JH and JP did the literature search and selection, data extraction, and quality evaluation. JH and LB analyzed and 
interpreted the data. JH, SS, FZ, NK, EB, and LB drafted or revised the manuscript. All authors read and approved the final manuscript.

\section{Funding}

This research was supported by Grant from the National Natural Science Foundation of China (NSFC 81501642) and two Grants from the administration of Science and Technology in Sanya City, Hainan Province, China (2017YW12 and 2017YD16).

This research was also supported by the Department of Anesthesia, Critical Care and Pain Medicine (Massachusetts General Hospital, Boston, Massachusetts, USA) and the National Institutes of Health (National Heart, Lung, and Blood Institute K23 HL128882-01A1).

\section{Availability of data and materials}

The datasets used in this study are available from the first author or corresponding author on request.

\section{Ethics approval and consent for participation}

Not applicable.

\section{Consent for publication}

Not applicable.

\section{Competing interests}

LB's salary is partially supported by NIH/NHLBI 1 K23 HL128882-01A1. Other authors declare that they have no competing interests.

\section{Author details}

${ }^{1}$ Department of Anesthesia, Critical Care and Pain Medicine, Massachusetts General Hospital, 55 Fruit Street, Boston, MA, USA. ${ }^{2}$ Department of Critical Care Medicine, Chinese PLA General Hospital, 28 Fuxing Road, Beijing, China. ${ }^{3}$ Department of Anesthesia and Critical Care Medicine, Cardiology Research Institute, Tomsk National Research Medical Center, Russian Academy of Sciences, 11 la Kievskaya St., Tomsk 634012, Russia. ${ }^{4}$ División de Anestesiología, Escuela de Medicina, Pontificia Universidad Católica de Chile, Santiago, Chile.

\section{Received: 27 August 2019 Accepted: 13 November 2019} Published online: 21 November 2019

\section{References}

1. Billings FTT, Hendricks PA, Schildcrout JS, Shi Y, Petracek MR, Byrne JG, et al. High-dose perioperative atorvastatin and acute kidney injury following cardiac surgery: a randomized clinical trial. JAMA. 2016;315(9):877-88.

2. Zarbock A, Schmidt C, Van Aken H, Wempe C, Martens S, Zahn PK, et al. Effect of remote ischemic preconditioning on kidney injury among high-risk patients undergoing cardiac surgery: a randomized clinical trial. JAMA. 2015;313(21):2133-41.

3. Bove T, Zangrillo A, Guarracino F, Alvaro G, Persi B, Maglioni E, et al. Effect of fenoldopam on use of renal replacement therapy among patients with acute kidney injury after cardiac surgery: a randomized clinical trial. JAMA. 2014;312(21):2244-53.

4. Meersch M, Schmidt C, Hoffmeier A, Van Aken H, Wempe C, Gerss J, et al. Prevention of cardiac surgery-associated AKI by implementing the KDIGO guidelines in high risk patients identified by biomarkers: the PrevAKI randomized controlled trial. Intensive Care Med. 2017;43(11):1551-61.

5. Vermeulen Windsant IC, Hanssen SJ, Buurman WA, Jacobs MJ. Cardiovascular surgery and organ damage: time to reconsider the role of hemolysis. J Thorac Cardiovasc Surg. 2011;142(1):1-11.

6. Vermeulen Windsant IC, de Wit NC, Sertorio JT, van Bijnen AA, Ganushchak YM, Heijmans JH, et al. Hemolysis during cardiac surgery is associated with increased intravascular nitric oxide consumption and perioperative kidney and intestinal tissue damage. Front Physiol. 2014;5:340.

7. Wessel DL, Adatia I, Giglia TM, Thompson JE, KulikTJ. Use of inhaled nitric oxide and acetylcholine in the evaluation of pulmonary hypertension and endothelial function after cardiopulmonary bypass. Circulation. 1993;88(5 Pt 1):2128-38.
8. Ahmad A, Dempsey SK, Daneva Z, Azam M, Li N, Li PL, et al. Role of nitric oxide in the cardiovascular and renal systems. Int J Mol Sci. 2018;19:9.

9. Nelin LD, Potenziano JL. Inhaled nitric oxide for neonates with persistent pulmonary hypertension of the newborn in the CINRGI study: time to treatment response. BMC Pediatr. 2019;19(1):17.

10. Hunt $J$, Bronicki RA, Anas N. Role of inhaled nitric oxide in the management of severe acute respiratory distress syndrome. Front Pediatr. 2016:4:74.

11. James C, Millar J, Horton S, Brizard C, Molesworth C, Butt W. Nitric oxide administration during paediatric cardiopulmonary bypass: a randomised controlled trial. Intensive Care Med. 2016;42(11):1744-52.

12. Checchia PA, Bronicki RA, Muenzer JT, Dixon D, Raithel S, Gandhi SK, et al. Nitric oxide delivery during cardiopulmonary bypass reduces postoperative morbidity in children - a randomized trial. J Thorac Cardiovasc Surg. 2013;146(3):530-6.

13. Rajek A, Pernerstorfer T, Kastner J, Mares P, Grabenwoger M, Sessler DI, et al. Inhaled nitric oxide reduces pulmonary vascular resistance more than prostaglandin E(1) during heart transplantation. Anesth Analg. 2000;90(3):523-30.

14. Zhou HL, Zhang R, Anand P, Stomberski CT, Qian Z, Hausladen A, et al. Metabolic reprogramming by the S-nitroso-CoA reductase system protects against kidney injury. Nature. 2019;565(7737):96-100.

15. Ahmad A, Sattar MA, Rathore HA, Abdulla MH, Khan SA, Abdullah NA et al. Enhanced expression of endothelial nitric oxide synthase in the myocardium ameliorates the progression of left ventricular hypertrophy in L-arginine treated Wistar-Kyoto rats. J Physiol Pharmacol. 2016;67(1):31-44

16. Berra L, Pinciroli R, Stowell CP, Wang L, Yu B, Fernandez BO, et al. Autologous transfusion of stored red blood cells increases pulmonary artery pressure. Am J Respir Crit Care Med. 2014;190(7):800-7.

17. Minneci PC, Deans KJ, Zhi H, Yuen PS, Star RA, Banks SM, et al. Hemolysis-associated endothelial dysfunction mediated by accelerated NO inactivation by decompartmentalized oxyhemoglobin. J Clin Investig. 2005;115(12):3409-17.

18. Lei C, Berra L, Rezoagli E, Yu B, Dong H, Yu S, et al. Nitric oxide decreases acute kidney injury and stage 3 chronic kidney disease after cardiac surgery. Am J Respir Crit Care Med. 2018;198(10):1279-87.

19. Kamenshchikov N. Nitric oxide in CPB for renal protection in cardiac surgery (NephroNO). NCT03527381.

20. Ruan SY, Huang TM, Wu HY, Wu HD, Yu CJ, Lai MS. Inhaled nitric oxide therapy and risk of renal dysfunction: a systematic review and metaanalysis of randomized trials. Crit Care (London, England). 2015;19:137.

21. Fernandes JL, Sampaio RO, Brandao CM, Accorsi TA, Cardoso LF, Spina GS, et al. Comparison of inhaled nitric oxide versus oxygen on hemodynamics in patients with mitral stenosis and severe pulmonary hypertension after mitral valve surgery. Am J Cardiol. 2011;107(7):1040-5.

22. Potapov E, Meyer D, Swaminathan M, Ramsay M, El Banayosy A, Diehl C, et al. Inhaled nitric oxide after left ventricular assist device implantation: a prospective, randomized, double-blind, multicenter, placebo-controlled trial. J Heart Lung Transplant. 2011;30(8):870-8.

23. Moher D, Liberati A, Tetzlaff J, Altman DG. Preferred reporting items for systematic reviews and meta-analyses: the PRISMA statement. BMJ (Clinical research ed). 2009:339:b2535.

24. Higgins JP, Altman DG, Gotzsche PC, Juni P, Moher D, Oxman AD, et al. The Cochrane Collaboration's tool for assessing risk of bias in randomised trials. BMJ (Clinical research ed). 2011;343:d5928.

25. Greco TBZG, Gemma M, et al. How to impute study-specific standard deviations in meta-analyses of skewed continuous endpoints? World J Meta-Anal. 2015;3:215-24.

26. Higgins JPT GSe. Cochrane handbook for systematic reviews of interventions version 5.1.0 [updated March 2011]. The Cochrane Collaboration. 2011. http://handbook.cochrane.org.

27. Jin ZC, Zhou XH, He J. Statistical methods for dealing with publication bias in meta-analysis. Stat Med. 2015;34(2):343-60.

28. Borenstein MHL, Higgins JPT, et al. Introduction to meta-analysis. Chichester: Wiley; 2009

29. Bradburn MJ, Deeks JJ, Berlin JA, Russell Localio A. Much ado about nothing: a comparison of the performance of meta-analytical methods with rare events. Stat Med. 2007;26(1):53-77. 
30. Wetterslev J, Jakobsen JC, Gluud C. Trial Sequential analysis in systematic reviews with meta-analysis. BMC Med Res Methodol. 2017;17(1):39.

31. Kamenshchikov NO, Mandel IA, Podoksenov YK, Svirko YS, Lomivorotov $\mathrm{V}$, Mikheev SL, et al. Nitric oxide provides myocardial protection when added to the cardiopulmonary bypass circuit during cardiac surgery: randomized trial. J Thorac Cardiovasc Surg. 2018;157:2328.

32. Perrin G, Roch A, Michelet P, Reynaud-Gaubert M, Thomas P, Doddoli C, et al. Inhaled nitric oxide does not prevent pulmonary edema after lung transplantation measured by lung water content: a randomized clinical study. Chest. 2006;129(4):1024-30.

33. Vercaemst L. Hemolysis in cardiac surgery patients undergoing cardiopulmonary bypass: a review in search of a treatment algorithm. J Extra Corpor Technol. 2008;40(4):257-67.

34. Rezoagli E, Ichinose F, Strelow S, Roy N, Shelton K, Matsumine R, et al. Pulmonary and systemic vascular resistances after cardiopulmonary bypass: role of hemolysis. J Cardiothorac Vasc Anesth. 2017;31(2):505-15.

35. Reiter CD, Wang X, Tanus-Santos JE, Hogg N, Cannon RO 3rd, Schechter AN, et al. Cell-free hemoglobin limits nitric oxide bioavailability in sicklecell disease. Nat Med. 2002;8(12):1383-9.

36. Rother RP, Bell L, Hillmen P, Gladwin MT. The clinical sequelae of intravascular hemolysis and extracellular plasma hemoglobin: a novel mechanism of human disease. JAMA. 2005;293(13):1653-62.

37. Zadek F, Spina S, Hu J, Berra L. Recommended reading from the Massachusetts general hospital, department of anesthesia, critical care and pain medicine fellows. Am J Respir Crit Care Med. 2019;200:628-30.

38. Troncy E, Francoeur M, Salazkin I, Yang F, Charbonneau M, Leclerc G, et al. Extra-pulmonary effects of inhaled nitric oxide in swine with and without phenylephrine. Br J Anaesth. 1997;79(5):631-40.

39. Matsuo $\mathrm{N}$. The role of intrapulmonary nitric oxide generation in the development of adult respiratory distress syndrome. Surg Today. 1999;29(10):1068-74.

40. Gozdzik W, Albert J, Harbut P, Zielinski S, Ryniak S, Lindwall R, et al. Prolonged exposure to inhaled nitric oxide transiently modifies tubular function in healthy piglets and promotes tubular apoptosis. Acta Physiol (Oxford, England). 2009:195(4):495-502.

41. Valvini EM, Young JD. Serum nitrogen oxides during nitric oxide inhalation. Br J Anaesth. 1995;74(3):338-9.

42. Liu C, Zhao W, Christ GJ, Gladwin MT, Kim-Shapiro DB. Nitric oxide scavenging by red cell microparticles. Free Radical Biol Med. 2013;65:1164-73.

43. Sundd P, Gladwin MT, Novelli EM. Pathophysiology of sickle cell disease. Ann Rev Pathol. 2019;14:263-92.

44. Young JD, Dyar O, Xiong L, Howell S. Methaemoglobin production in normal adults inhaling low concentrations of nitric oxide. Intensive Care Med. 1994;20(8):581-4.

45. Fattouch K, Sbraga F, Sampognaro R, Bianco G, Gucciardo M, Lavalle $C$, et al. Treatment of pulmonary hypertension in patients undergoing cardiac surgery with cardiopulmonary bypass: a randomized, prospective, double-blind study. J Cardiovasc Med (Hagerstown). 2006;7(2):119-23.
46. Kirbas A, Yalcin Y, Tanrikulu N, Gurer O, Isik O. Comparison of inhaled nitric oxide and aerosolized iloprost in pulmonary hypertension in children with congenital heart surgery. Cardiol J. 2012;19(4):387-94.

47. Knothe C, Scholz S, Zickmann B, Marquart B, Dapper F, Hempelmann G. $\mathrm{NO}$ inhalation in heart surgery procedures: relevance for right heart function? Der Anaesthesist. 1996;45(3):240-8.

48. Solina A, Papp D, Ginsberg S, Krause T, Grubb W, Scholz P, et al. A comparison of inhaled nitric oxide and milrinone for the treatment of pulmonary hypertension in adult cardiac surgery patients. J Cardiothorac Vasc Anesth. 2000;14(1):12-7.

49. Fattouch K, Sbraga F, Bianco G, Speziale G, Gucciardo M, Sampognaro $\mathrm{R}$, et al. Inhaled prostacyclin, nitric oxide, and nitroprusside in pulmonary hypertension after mitral valve replacement. J Card Surg. 2005;20(2):171-6.

50. Prendergast B, Scott DH, Mankad PS. Beneficial effects of inhaled nitric oxide in hypoxaemic patients after coronary artery bypass surgery. Eur J Cardiothorac Surg. 1998;14(5):488-93.

51. Lei $C$, Berra $L$, Xiong $L$, Zapol WM. Reply to Coutrot et al.: is nitric oxide nephro- or cardioprotective? Am J Respir Crit Care Med. 2019:199(11):1442-3.

52. Sardo S, Osawa EA, Finco G, Gomes Galas FRB, de Almeida JP, Cutuli $\mathrm{SL}$, et al. Nitric oxide in cardiac surgery: a meta-analysis of randomized controlled trials. J Cardiothorac Vasc Anesth. 2018;32(6):2512-9.

53. Irokawa M, Nishinaga M, Ikeda U, Shinoda Y, Suematsu M, Gouda N, et al. Endothelial-derived nitric oxide preserves anticoagulant heparan sulfate expression in cultured porcine aortic endothelial cells. Atherosclerosis. 1997;135(1):9-17.

54. Marcucci L. Avoiding common ICU errors. Philadelphia: Wolters Kluwer/ Lippincott Williams \& Wilkins; 2007.

55. Bellomo R, Ronco C, Kellum JA, Mehta RL, Palevsky P. Acute renal failuredefinition, outcome measures, animal models, fluid therapy and information technology needs: the Second International Consensus Conference of the Acute Dialysis Quality Initiative (ADQI) Group. Crit Care (London, England). 2004;8(4):R204-12.

56. Mehta RL, Kellum JA, Shah SV, Molitoris BA, Ronco C, Warnock DG, et al. Acute Kidney Injury Network: report of an initiative to improve outcomes in acute kidney injury. Crit Care (London, England). 2007;11(2):R31.

57. Kidney Disease: Improving Global Outcomes (KDIGO) Acute Kidney Injury Work Group. KDIGO Clinical Practice Guideline for Acute Kidney Injury. Kidney Int. 2012;Suppl(2):1-138.

58. Luther MK, Timbrook TT, Caffrey AR, Dosa D, Lodise TP, LaPlante KL. Vancomycin plus piperacillin-tazobactam and acute kidney injury in adults: a systematic review and meta-analysis. Crit Care Med. 2018;46(1):12-20.

\section{Publisher's Note}

Springer Nature remains neutral with regard to jurisdictional claims in published maps and institutional affiliations.

\section{Submit your manuscript to a SpringerOpen ${ }^{\circ}$ journal and benefit from:}

- Convenient online submission

- Rigorous peer review

- Open access: articles freely available online

- High visibility within the field

- Retaining the copyright to your article

Submit your next manuscript at springeropen.com 